\title{
Characterisation of National Immunisation Programmes (NIPs) in the context of Public Health Emergencies (PHEs): A Case Study of 13 Countries in the WHO African Region
}

\author{
Viola Chepkurui ( $\nabla$ violachepkurui2@gmail.com ) \\ University of Cape Town https://orcid.org/0000-0002-4408-1653 \\ Edina Amponsah-Dacosta \\ University of Cape Town School of Public Health and Family Medicine \\ Haddison Christiana Eposi \\ Regional Delegation of Public Health, Centre Region, Cameroon \\ Benjamin Mugo Kagina \\ University of Cape Town School of Public Health and Family Medicine
}

\section{Research}

Keywords: public health emergencies, national immunisation programmes, WHO-Afro, African countries, immunisation

Posted Date: December 29th, 2020

DOI: https://doi.org/10.21203/rs.3.rs-135261/v1

License: () (1) This work is licensed under a Creative Commons Attribution 4.0 International License. Read Full License 


\section{Abstract}

Background

In the World Health Organisation African region (WHO-Afro), multiple public health emergencies (PHEs) are experienced annually. PHEs are known to affect the provision of health services including immunisation. To our knowledge, there is limited information on the characterisation of PHEs and the performance of national immunisation programmes (NIPs) in countries within the WHO-Afro. This study assessed PHEs (armed conflicts, disasters, and disease outbreaks) and the performance of NIPs within PHE contexts using global and regional immunisation targets.

Methods

Countries recorded to have benefitted from PHE mitigation funds from the African Public Health Emergency Fund (APHEF) were used as case studies.

Data on PHEs and immunisation indicators between 2010 and 2019 in the selected countries were extracted from different PHE electronic databases and the WHO/UNICEF immunisation database, respectively.

The PHEs and immunisation indicators were stratified by country and summarised using descriptive statistics. The Mann-Whitney $U$ test was carried out to determine the association between the frequency of PHEs and the performance of NIPs. Statistical significance was defined at p-value $<0.05$.

Results

Between 2010 and 2019 there were a total of 175 disease outbreaks, 288 armed conflicts, and 318 disasters in the 13 countries selected as case studies. The Democratic Republic of Congo had the highest total PHE count $(n=208)$, while Liberia had the lowest $(n=20)$. Only three of the 13 countries had a median coverage value for the third dose of the combined Diphtheria, Tetanus, and Pertussis vaccine (DTP3) that had attained the target for $\geq 90 \%$ immunisation coverage.

Higher counts of armed conflict and total PHEs were associated with not meeting the immunisation targets for national DTP3 coverage of $\geq 90 \%$ and Maternal and Neonatal Tetanus (MNT) elimination, $p<0.01$. Higher disaster counts were also associated with not attaining MNT elimination, $\mathrm{p}=0.03$.

Conclusion

PHEs are prevalent in the WHO-Afro, irrespective of the level of a country's immunisation maturity. In absence of effective interventions, the PHEs have the potential to derail the progress of NIPs in the WHO-Afro. As we transition towards the Immunisation Agenda 2030, we recommend that the WHO-Afro prioritises interventions to mitigate the impacts of PHEs on the NIPs.

\section{Background}

Public Health Emergencies (PHEs) are recognised as one of the major threats to global public health security (1). Globally, numerous countries experience different types of PHEs which range from infectious disease outbreaks, natural disasters (e.g. floods) and human-induced hazards (e.g. armed conflicts) (2). In the WHO-Afro, more than 100 PHEs are reported to occur annually $(3,4)$. A PHE is described as a situation that impacts the lives and well-being of a large number of people and which often necessitates substantial multi-sectoral assistance; as it presents a critical threat to the health, safety, and wellbeing of the people $(2,5)$. The unprecedented occurrence of the Coronavirus Disease 2019 (COVID-19) pandemic, which is classified as a PHE of international concern (6), has highlighted more than ever that PHEs do transcend international boundaries and have negative impacts on various facets of society including public health $(2,3)$. The impact PHEs have on public health cannot be understated, given they cause widespread disruption to both the broader health system and provision of health services (7-9) including that of immunisation $(10,11)$.

The disruption to national immunisation programmes (NIPs) experienced in countries with PHEs has been associated with suboptimal immunisation coverage rates $(7,12,13)$. The plummeting vaccination coverage witnessed during PHEs is due to many factors. These factors include reduced access to immunisation services, destroyed and disrupted vaccine logistic systems, depleted and diverted financial and human resources for immunisation, and reduced public trust towards immunisation $(7,12,13)$. Many of these factors have eminently featured during the COVID-19 pandemic (14-16). The sub-optimal immunisation coverage rates, also, create large pockets of unimmunised and under-immunised children and adults thereby lowering herd immunity (17-19). In addition, PHEs can result to poor sanitation and overcrowding which are risk factors for outbreaks of Vaccine-Preventable Diseases (VPDs) (19-22). Therefore, countries affected by PHEs are reported to lag in meeting global and regional immunisation targets aimed at control, elimination, and eradication of VPDs (23, 24).

The Global Vaccine Action Plan (GVAP) was developed in 2011 to actualise the vision of the Decade of Vaccines (DoV) for having a world where individuals and communities will be able to enjoy lives free from VPDs (25). The Regional Strategic Plan for Immunisation (RSPI), is a WHO-Afro contextualised immunisation framework adopted from the GVAP with goals for attainment by 2020 (26). Although through the two immunisation frameworks the WHO-Afro has achieved substantive gain in immunisation that includes the successful eradication of wild poliovirus disease (27), many targets remain unmet, owing to amidst other factors the prevalent PHEs (28). During the DoV there has been growing concern on the possible role PHEs play in delaying achievement for set immunisation targets $(24,28,29)$. According to reports by the WHO, Strategic Advisory Groups of Experts (SAGE) in immunisation, PHEs are recognised as one of the major shifts during the 2010-2020 period and a key driver of inequity in immunisation access between and within countries (24, 29). In cognisance of prevalent PHE in the WHO-Afro, including the COVID-19 pandemic, and the end of the DoV in 2020, there is need to take stock of immunisation performance in countries experiencing PHEs. The evidence generated would advance the understanding that is critical in strengthening NIPs in the context of PHEs. 
In as much as PHEs have been recognised to have repercussions on NIPs, inadequate focus has been given on synthesising evidence in PHEs affected settings. A limited number of studies have attempted to describe immunisation in countries affected by PHEs, however, a majority are restricted to single types of PHEs, especially armed conflict and single immunisation indicators $(7,9,12,30)$. To the best of our knowledge this will be the first study that aims to characterise NIPs in the WHO-Afro experiencing PHEs; using three different types of PHEs (armed conflicts, disease outbreaks, and disasters) and the DoV immunisation targets to account for the performance of NIPs.

\section{Methods Study design}

Retrospective case study using secondary data on immunisation indicators and PHEs.

\section{Study population}

Countries in the WHO-Afro that have received funding from the African Public Health Emergency Fund (APHEF) between 2012 and 2019 were used as case studies.

\section{Data sources}

The study utilised secondary data from different sources available as of July 2020 and reported from 2010 to 2019 (Fig. 1)

Data on immunisation indicators outlined in the DoV were obtained through country reports made to the World Health Organisation (WHO) and the United Nations Children's Fund (UNICEF) using the Joint Reporting Form (JRF) (31).

The APHEF had supported three types of PHEs namely armed conflict, disasters, and disease outbreaks (32). Data was collated from different electronic databases reporting on these three types of PHEs. The databases used were:

1. The Emergency Events Database (EM-DAT) from the Centre for Research on the Epidemiology of Disasters which reports on natural and technological disasters, for the study these two disaster subtypes were collectively referred to as disasters (33).

2. The Uppsala Conflict Data Program (UCDP), a database that curates data on various types of armed conflicts namely state conflicts, one-sided violence conflicts and, non-state conflicts (34).

3. The WHO Emergency Preparedness and Response an integrated global alert and response system that reports on occurrences of disease outbreaks (35), which was corroborated with data from the Program for Monitoring Emerging Diseases Mail (PROMED- Mail) (36).

\section{The determinant variables}

The counts of the three types of PHEs namely disasters, armed conflicts, and disease outbreaks, and the total PHEs count (the cumulative total count of the three PHE types) were used as the main determinant variables.

\section{Outcome variables}

The following selected immunisation indicators implemented for the DoV (Fig. 1) were used as the study outcome variables:

1. The combined Diphtheria, Tetanus, and Pertussis vaccine (DTP) coverage rates whwere used as proxies to gauge the strength and reach of routine immunisation programmes (25) including:

i) Having $\geq 90 \%$ national coverage for the third dose of the DTP (DTP3)

ii) Drop-out rate between the first dose of the DTP (DTPand DTP3

2. Introduction of new and underutilised vaccines (25); three vaccines were considered for study and used as proxies, they included the Rotavirus vaccine, Pneumococcal Conjugate Vaccine (PCV), and Human Papillomavirus (HPV) vaccine.

3. The attainment status for elimination of Maternal and Neonatal Tetanus (MNT), one of the targeted VPDs for regional and global elimination (25).

4. The establishment of national immunisation technical advisory group (NITAG) was used to gauge immunisation prioritisation and country ownership for NIPs. Data for this variable was obtained on both the existence and functionality of a NITAG. The functionality of a NITAG is pegged on an existing country NITAG meeting 6 minimum criteria as outlined by the WHO including the (A) administrative basis for the advisory group, (B) formal written terms of reference, (C) at least five different areas of expertise represented among NITAG core members, (D) at least one meeting per year, (E) circulation of the agenda documents at least one week before meetings, and $(\mathbf{F})$ the mandatory disclosure of any conflict of interest. Each of the 6 outlined criteria needs to be satisfied for a country's NITAG to be merited as functional (43).

5. Immunisation maturity grid; which was used to rate immunisation systems and identify gaps in the performance of NIPs (37).

\section{Data synthesis and analysis}

To establish any underlying trends in the total PHE count for each of the study countries, the study duration was stratified into three-time points in 2010 at the beginning of the study, in 2014 after five years, and in 2019- ten years and the end of the study.

The three types of PHEs were stratified by country using stacked bar plots in each of the study years to establish both the overall prevalence for each of the three types of PHEs and identify the individual country-specific prevalence for a given PHE. 
All the statistical analysis and visualisation of study data were done using the R software version 4.0.2 (R Core Team, 2020). The selected DoV immunisation indicators were stratified by country and summarised using descriptive statistics such as the mean (Standard Deviation (SD)) and/or the median (Interquartile range (IQR)) for numerical continuous variables depending on distribution, and counts and proportions, used for categorical variables. The results were presented in a table. We also used, a line graph to establish the temporal trends in the national and regional DTP3 coverage indicator.

Two groups were created for the target immunisation indicators outlined in the DoV. The two groups were based on the number of years from 2010 to 2019 that each of the selected countries had either met a specific target or had failed to meet the target. Labels used for the two target groups were "target met"Yes, and "target not met"- No. The distribution of the three types of PHEs and the total PHE counts were compared across the two groups using the MannWhitney U group-comparison test, as the data had a non-normal distribution. Statistical significance for the tests was defined at $p$-value $<0.05$. The distribution of the total PHE count in the selected countries from 2010 to 2019 was also, compared across the two immunisation target groups using boxplots.

\section{Results}

\section{Countries benefiting from the APHEF}

As of 2017, the APHEF had supported 13 countries within the WHO-Afro. The 13 countries were Burundi, Zimbabwe, the Central African Republic, South Sudan, Guinea, Cameroon, Liberia, Sierra Leone, Democratic Republic of Congo, Malawi, Niger, Angola, and Ethiopia.

\section{PHEs reported between 2010 and 2019}

Between 2010 and 2019 PHEs were present in each of the study population countries and varied in count across the countries (Fig. 2).

The highest total PHE count was recorded in the Democratic Republic of Congo $(n=208)$, while the lowest total PHE count was recorded in Liberia ( $n=20)$ (Fig. 2). Despite being the youngest country in the WHO-Afro, South Sudan (gained independence in 2011), had the second-highest total PHE count at ( $\mathrm{n}=99$ ).

\section{Total PHE counts across three time periods}

A snapshot of the total PHE count in the 13 countries in 2010, 2014, and 2019 showed the individual country trends at the beginning of the study period in 2010, after five years, and at ten years in 2019. The PHE counts fluctuated across the study periods. While eight countries witnessed a decrease in the PHE count in 2014 compared to 2010, nine countries in 2019 recorded an increase in the PHE count compared to 2014 (Table 1).

\section{Types of PHEs}

Three types of PHEs namely armed conflicts, disasters, and disease outbreaks were extracted from databases and summarised (Fig. 3). In the 13 countries and from 2010 to 2019, a total count of $n=175, n=288$, and $n=318$ for disease outbreaks, armed conflicts, and disasters was recorded respectively.

A summary of the annual distribution of the three types of PHEs occurring in each country during the study period is shown (Fig. 3). Overall, counts of armed conflicts $(n=89)$, disasters $(n=91)$, and disease outbreaks $(n=28)$ were highest in the Democratic Republic of Congo (Fig. 3$)$. In general, and with exception of the Democratic Republic of Congo, armed conflicts and disease outbreaks were majorly prevalent in all other countries for the entire study period (Fig. 3 ).

\section{Performance of NIPs in the period of PHEs}

The target immunisation indicators for the DoV were used to assess the performance of NIPs in the study countries from 2010 to 2019.

\section{National DTP3 coverage}

The DTP3 coverage was used as a proxy indicator for the performance of NIPs in meeting national and regional immunisation coverage targets.

The recorded trend in the annual national DTP3 coverage estimates in each of the 13 countries points to fluctuating patterns during the entire study period (Fig. 4).

Only three (Burundi, Malawi, and Zimbabwe ) of the 13 countries had a median national DTP3 coverage value that had met the $\geq 90 \%$ immunisation coverage DoV target (Table 2). In addition to this, Burundi's annual DTP3 coverage rates were found to supersede the $\geq 90 \%$ immunisation coverage target during the entire study period (Fig. 4).

The WHO-Afro DTP3 coverage between 2010 and 2019 stagnated at around the average 72\% mark (Fig. 4). Six countries, (the Central African Republic, the Democratic Republic of Congo, South Sudan, Guinea, Angola, and Ethiopia) had national DTP3 coverage rates below the regional DTP3 stagnation point in the entire study period (Fig. 4). While four countries maintained a coverage rate above that of the region including Burundi, Malawi, Zimbabwe, and Sierra Leone. The remaining three countries (Liberia, Cameroon, and Niger) had fluctuating immunisation coverage rates.

Two countries were recorded to have major dips, followed by major increases in their national DTP3 vaccine coverage in some of the study years; they were the Central African Republic and Liberia, these dips occurred in 2013 and 2014 respectively (Fig. 4).

\section{Percentage drop-out rates between DTP1 and DTP3}


To gauge accessibility and utilisation of immunisation services we used drop-out rates between DTP1 and DTP3. Three countries (The Central African Republic, South Sudan, and Angola) had drop-out rates above 10\%. The highest drop-out rate in the ten-year study period was recorded in the Central African Republic, with a median [IQR] of 24.00 [9.50] (Table 2).

Table 2

Descriptive summary of NIP related immunisation indicators between 2010 and 2019 stratified by country

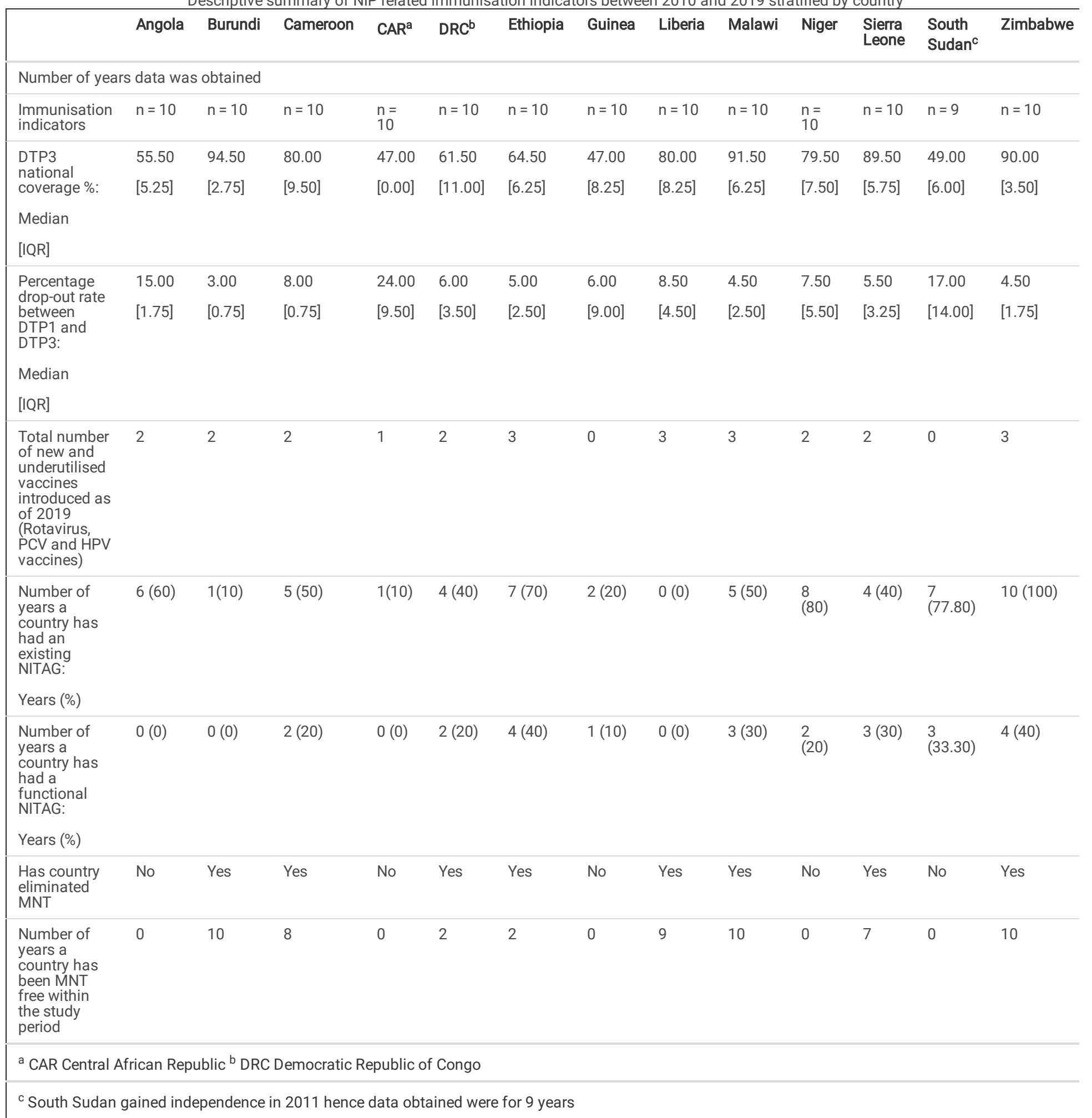

\section{Introduction of new and underutilised vaccines}

To gauge the progress of countries in the introduction of new vaccines in their NIPs three vaccines: The Rotavirus, PCV, and the HPV vaccines were considered. The PCV and the Rotavirus vaccine were first introduced in the WHO-Afro between the years 2008 and 2009, while the HPV vaccine was first introduced in 2014. Among the thirteen countries; eleven countries had introduced PCV, while seven countries had introduced the Rotavirus vaccine to their immunisation schedule between 2010 and 2014. Only four countries had introduced the HPV vaccine in the second half of the study period (2015-2019). The HPV vaccine is the newest to be introduced in the NIPs of countries in the WHO-Afro. 
Ethiopia, Liberia, Malawi, and Zimbabwe had introduced all three vaccines by 2019. While Guinea and South Sudan were yet to introduce any of the three vaccines in their NIPs by 2019 (Table 2).

\section{Elimination of MNT}

To monitor the performance of countries in meeting global and regional elimination targets for key VPDs the elimination of MNT was considered. As of 2019, 8 of the 13 countries had attained MNT elimination. Countries yet to eliminate MNT by 2019 were Angola, the Central African Republic, Guinea, Niger, and South Sudan (Table 2).

\section{Establishment of NITAGs}

To gauge progress towards country ownership of NIPs and immunisation prioritisation, the establishment of NITAGs in the study countries were examined

during the entire study period.

Except for Zimbabwe, none of the countries had an existing NITAG for the entire ten-year study period. Niger, South Sudan, Ethiopia, and Angola had existing NITAGs for over half of the study period. The remaining countries had existing NITAGs for less than half of the study period, apart from Liberia which had no existing NITAG for the ten-year study period (Table 2).

All the 13 study countries had functional NITAGs for less than half of the study period (Table 2).

\section{Immunisation maturity Grid}

The immunisation maturity grid is a six-component tool developed by the WHO aimed at attaining control, elimination, and eradication of key VPDs in the African continent. As of 2018, the NIPs of the 13 countries were classified into four maturity levels as shown in Table 3.

Table 3

Classification of countries according to their immunisation maturity grid

\begin{tabular}{|lll|}
\hline $\begin{array}{l}\text { Immunisation } \\
\text { maturity grid }\end{array}$ & Countries in the maturity grid & Rating criteria \\
\hline Level 1 & $\begin{array}{l}\text { The Central African Republic, South Sudan, Sierra Leone, } \\
\text { and Liberia }\end{array}$ & Countries with very weak immunisation systems \\
\hline Level 2 & Guinea, Angola, and the Democratic Republic of Congo & $\begin{array}{l}\text { Countries with significant deficiencies in immunisation service } \\
\text { delivery }\end{array}$ \\
\hline Level 3 & Cameroon, Niger, Ethiopia, and Malawi & $\begin{array}{l}\text { Countries with targeted areas for improvement in their immunisation } \\
\text { programmes }\end{array}$ \\
\hline Level 4 & Burundi and Zimbabwe & Countries with strong and robust immunisation systems \\
\hline a Adopted from the Business case for WHO immunisation activities on the African continent 2018 (37)
\end{tabular}

\section{The association between PHEs and NIP performance}

We compared the distribution in count for the three types of PHEs and the total PHEs across the two groups created from the DoV immunisation targets in the 13 countries from 2010 to 2019.

Higher armed conflict counts were associated with not meeting the immunisation targets for national DTP3 coverage of $\geq 90 \%$ and MNT elimination, $p<0.01$, ( Table 4).

Higher disaster counts were also, associated with not meeting the target for MNT elimination, $p=0.03$, (Table 4) 
Table 4

A Comparison of PHE count across two target groups of immunisation indicators outlined for DoV

\begin{tabular}{|c|c|c|c|c|c|c|c|c|c|c|c|c|}
\hline & \multicolumn{3}{|c|}{$\begin{array}{l}\text { Target for } \geq 90 \% \text { national } \\
\text { DTP3 coverage }\end{array}$} & \multicolumn{3}{|c|}{ Target for MNT elimination } & \multicolumn{3}{|c|}{$\begin{array}{l}\text { Target to have a functional } \\
\text { NITAG }\end{array}$} & \multicolumn{3}{|c|}{$\begin{array}{l}\text { Target to introduce at least one new or } \\
\text { underutilised vaccine }^{b}\end{array}$} \\
\hline & $\begin{array}{l}\text { Target not } \\
\text { met }\end{array}$ & $\begin{array}{l}\text { Target } \\
\text { met }\end{array}$ & $\begin{array}{l}\mathrm{p}- \\
\text { value }\end{array}$ & $\begin{array}{l}\text { Target } \\
\text { not met }\end{array}$ & $\begin{array}{l}\text { Target } \\
\text { met }\end{array}$ & $\begin{array}{l}\mathrm{p}- \\
\text { value }\end{array}$ & $\begin{array}{l}\text { Target } \\
\text { not met }\end{array}$ & $\begin{array}{l}\text { Target } \\
\text { met }\end{array}$ & $\begin{array}{l}\mathrm{p}- \\
\text { value }\end{array}$ & Target not met & Target met & $\mathrm{p}$-value \\
\hline & $n^{a}=102$ & $n^{a}=27$ & & $n^{a}=71$ & $\mathrm{n}^{\mathrm{a}}=58$ & & $\mathrm{n}^{\mathrm{a}}=105$ & $n^{a}=24$ & & $n^{a}=103$ & $\mathrm{n}^{\mathrm{a}}=24$ & \\
\hline \multicolumn{13}{|l|}{ PHE type } \\
\hline \multirow{2}{*}{$\begin{array}{l}\text { Armed } \\
\text { conflict } \\
\text { Median } \\
\text { [IQR] }\end{array}$} & 1 & 0 & \multirow{2}{*}{$<.01^{*}$} & 1 & 0 & \multirow{2}{*}{$\begin{array}{l}<.01^{*} \\
\end{array}$} & 0 & 0.5 & \multirow[t]{2}{*}{0.40} & \multirow{2}{*}{$\begin{array}{l}1 \\
{[3]}\end{array}$} & \multirow{2}{*}{$\begin{array}{l}0 \\
{[1]}\end{array}$} & \multirow[t]{2}{*}{0.05} \\
\hline & {$[5]$} & {$[0]$} & & {$[5.5]$} & [1] & & [3] & {$[5]$} & & & & \\
\hline Disaster & 2 & 2 & \multirow[t]{2}{*}{0.90} & 2 & 1 & \multirow[t]{2}{*}{$0.03^{*}$} & 2 & 2 & \multirow[t]{2}{*}{0.30} & 2 & 2 & \multirow[t]{2}{*}{0.60} \\
\hline $\begin{array}{l}\text { Median } \\
\text { [IQR] }\end{array}$ & [2] & [2] & & {$[2.5]$} & [2] & & {$[2]$} & {$[1]$} & & [2] & [2] & \\
\hline \multirow{2}{*}{$\begin{array}{l}\text { Disease } \\
\text { outbreak } \\
\text { Median } \\
\text { [IQR] }\end{array}$} & 1 & 1 & \multirow[t]{2}{*}{0.10} & 1 & 1 & \multirow[t]{2}{*}{0.90} & 1 & 2 & \multirow[t]{2}{*}{0.40} & 1 & 1 & \multirow[t]{2}{*}{0.60} \\
\hline & [2] & {$[1.5]$} & & [2] & [2] & & [2] & [3] & & [2] & {$[1]$} & \\
\hline \multirow{4}{*}{$\begin{array}{l}\text { Total } \\
\text { PHEs }^{\mathrm{c}} \\
\text { Median } \\
{[\mathrm{IQR}]}\end{array}$} & 5 & 3 & \multirow{4}{*}{$\begin{array}{l}<.01^{*} \\
-\end{array}$} & 5 & 3 & \multirow{4}{*}{$\begin{array}{l}< \\
0.01^{*}\end{array}$} & 4 & 5 & \multirow[t]{4}{*}{0.10} & 5 & 5 & \multirow[t]{4}{*}{0.06} \\
\hline & {$[6]$} & [2] & & [7] & [3] & & {$[5]$} & {$[6.5]$} & & [3] & [3] & \\
\hline & & & & & & & & & & & & \\
\hline & & & & & & & & & & & & \\
\hline \multicolumn{13}{|c|}{${ }^{*} \mathrm{p}$-value significant } \\
\hline \multicolumn{13}{|c|}{$\begin{array}{l}\text { a Between } 2010 \text { and } 2019 \text { each of the } 13 \text { countries contributed } 10 \text { years, except for South Sudan (gained independence in 2011), which contributed } 9 \\
\text { years, hence, the total number of years for all the } 13 \text { countries was } 129 .\end{array}$} \\
\hline \multicolumn{13}{|c|}{${ }^{b}$ For this target two years had no data as two countries had already introduced all the three new vaccines examined in the study in their preceding years } \\
\hline \multicolumn{13}{|c|}{${ }^{\mathrm{c}}$ This variable is a function of the total count of the armed conflict, disaster, and disease outbreak variables } \\
\hline $\begin{array}{l}\text { Higher to } \\
p<0.01\end{array}$ & $\begin{array}{l}\text { E counts } \\
\text { 4) and }(\mathrm{Fi}\end{array}$ & assoc & d with & t meetir & nunis & $\mathrm{n} \operatorname{tar}$ & for natic & DTP3 & rage & $\geq 90 \%$ and not & ining MNT & nation, \\
\hline
\end{tabular}

Higher counts of armed conflicts, disasters, disease outbreaks, and total PHEs were not associated with meeting the DoV immunisation targets for introducing new vaccines and the presence of functional NITAGs, $p>0.05$ (Table 4).

\section{Discussion}

The primary intent of the study was to characterise the NIPs of countries within the WHO-Afro experiencing PHEs using immunisation targets outlined for the DoV as proxy indicators. We found that PHEs were endemic during the entire study period and the performance of NIPs in the PHE endemic countries was variable, although mostly suboptimal. Additionally, higher total PHE and armed conflict counts were associated with not achieving the immunisation targets for $\geq 90 \%$ national DTP3 coverage and MNT elimination. Higher disaster counts were also associated with not eliminating MNT.

The endemicity of PHEs observed during the study period, agree with other reports on the recurrent and diverse nature of PHEs experienced in the WHO-Afro (4, 38). While armed conflict and disasters were found to have the highest cumulative count in our study, contrary, trends were observed in the WHO-Afro, with a majority of reported PHEs being that of disease outbreaks $(3,38,39)$. The discrepancy can be explained by findings from other studies done in similar settings, where disease outbreaks were noted to occasionally go unrecorded as they occur as twin PHEs, in the context of armed conflicts and disasters (2, 40).

Regardless of the immunisation maturity level, the overall performance of NIPs in the PHE endemic countries was variable but predominantly suboptimal. The fluctuating and the low national DTP3 coverage rates below the WHO-Afro DTP3 coverage stagnation point are synonymous with DTP3 coverage reports in other NIPs in the region during PHEs $(7,12,23)$. Similarly, the high DTP vaccine drop-out; classified as $\geq 10 \%$ (26), recorded in some of the NIPs, concur with findings from a study by Mugali et al. (41) in Afghanistan where high DTP drop-out rates were associated with conflict and insecurity. The introduction of the PCV and the Rotavirus vaccines into the NIPs of the study countries was high compared to the HPV vaccine. These findings are comparable to those in the region as $86 \%, 76 \%$, and $8 \%$ of GAVI eligible countries had introduced the PCV, Rotavirus, and the HPV vaccines respectively by 2017 (42). Delay in HPV vaccine introduction has been attributed elsewhere to the poor adoption of life-course immunisation, vaccine supply constraints, and pricing issues (17, 24) 
which stand exacerbated by PHEs (7). The outlier countries yet to introduce any of the three selected vaccines are potential key pointers to the contributing role PHEs play in delaying vaccine introductions into NIPs as raised by Grundy et al. in their study (7).

Despite the positive progress in NITAG establishment in the WHO-Afro (43), a non-consistent pattern in their existence and functionality simultaneously existed. Such inconsistent trends have been attributed in previous reports to the lack of political commitment and country ownerships of NIPs and the low NITAG financial investments, in general, and during PHEs $(43,44)$.

The elimination target for MNT was not met in countries with high counts of PHEs like South Sudan, the Central African Republic, Niger, Guinea, and Angola. The enlisted five countries constitute nearly $50 \%$ of the remaining global MNT elimination priority countries (45) and have similar trends with other MNT priority countries like Afghanistan and Yemen, where the presence of protracted PHEs have been blamed on delaying elimination (46).

Having higher armed conflict and total PHE counts were associated with not attaining the target for $\geq 90 \%$ national DTP3 coverage. These findings are comparable to those from studies conducted in similar contexts where armed conflicts were reported to be associated with poor immunisation coverage outcomes $(7,12,30)$. The findings further show that periods of higher counts of armed conflicts, disasters, and total PHEs were also associated with not eliminating MNT. Elimination of MNT in the WHO-Afro has been evasive to some extent, with most of the countries prioritised for MNT elimination being affected by PHEs (47-49). In other PHE endemic contexts, where MNT elimination remains unattained, low tetanus vaccine coverage among women of reproductive age, unhygienic birth practices, delayed treatment, and inadequate MNT surveillance have been cited to delay progress (48, 50,51$)$.

Higher counts of all the three types of PHEs and the total PHEs were not associated with meeting the immunisation targets of having functional NITAGs or the introduction of new vaccines. The lack of consistency in the existence and functionality of NITAGs is not uncommon as observed in other PHE prone contexts in the region (43). On the other hand, during PHEs, whereas the functionality of NITAGs may be compromised (44), the WHO recommends humanitarian immunisation teams to utilise the unique expertise and local knowledge of existing NITAG members (19). For the target to introduce new vaccines, a possible caveat may exist in interpreting association, as within the scope of this study, only three vaccines were selected out of a pool of new vaccines. Conversely, we equally recognise that despite PHE endemicity, most of the case study countries had performed relatively well in this target which is also credited as one of the WHO-Afro DoV successes $(24,29)$ owing to political commitment and strong immunisation investments (49). Arguably, such progressive performance noted in this DoV target, can offer a lesson; that the link between PHEs and immunisation performance may not be always absolute.

Our results should be interpreted in light of certain caveats. First, our study was limited to three broad types of PHEs, that may not be exhaustively representative of all types of PHE experienced in the study countries. Furthermore, the severity of the PHEs could not be accounted for as this level of data was not available. The WHO conventional PHE grade system for grading PHE severity was first availed for use in the WHO-Afro in 2017, which was towards the end of the study period. It should be noted that PHEs often overlap in the real-world context and it may be challenging to identify how a single PHE may have impacted the performance of immunisation programmes. Additionally, we may be unable to determine how previous PHEs experienced before the start of the study period in 2010 may have affected the NIPs in the selected countries.

Secondly, we used country generated reports from the WHO/UNICEF JRF to abstract data on DoV immunisation indicators. It is, possible that potential inaccuracies in the country data may have influenced the outcome of our study. However, this could not be avoided within the scope of this study. Data quality issues from country reports have been constantly highlighted as one of the major concerns by the WHO, SAGE in their annual DoV immunisation reports (24, $28,29)$.

Lastly, while associations between the occurrence of PHEs and the performance of immunisation programmes were inferred we cannot rule out with certainty the influence of other determinants of immunisation programme performance. It was also not possible to account for emergency responses aimed at providing immunisation services during PHEs. As such, our estimated results may represent a lower bound for the true effect of PHEs on immunisation.

Future research investigations should address these limitations to broaden the scope of evidence on the interactions that exist between PHEs and immunisation performance. We propose that future studies should further explore 1) how other types and grades of PHEs may variably impact immunisation performance, 2) immunisation performance at the sub-national level using immunisation data from localised communities where PHEs are recorded to occur, and 3) other determinants that may act together with PHEs to influence immunisation performance.

\section{Conclusion}

PHEs are endemically present in the WHO-Afro and form part of the eco-system in which NIPs exist. With the goal of extending immunisation to all individuals, countries experiencing PHEs within WHO-Afro may be excluded from reaping the full benefits of immunisation owing to unmet targets. Immunisation performance in countries where PHEs are endemic is largely suboptimal and not at par with envisioned immunisation targets for the DoV. As the DoV comes to an end in 2020 and as the Immunisation Agenda 2030 nears its launch, PHEs like the COVID-19 pandemic, armed conflicts, and disasters are a major threat to NIPs. Therefore, priority should be given to developing evidence-based interventions to mitigate the impacts of PHEs on NIPs. Such interventions may include the commitment by governments in the WHO-Afro to strengthen the resilience of NIPs against PHE challenges by investing in PHE prevention and mitigation initiatives like the APHEF. Characterising the performance of NIPs in PHE contexts is undoubtedly elemental in bridging the gap to equitable access to immunisation for all populations, irrespective of where they live.

\section{List Of Abbreviations}




\begin{tabular}{|ll|}
\hline APHEF & African Public Health Emergency Fund \\
\hline COVID-19 & Coronavirus Disease \\
\hline DTP1 & First dose of the combined Diphtheria, Tetanus, and Pertussis Vaccine \\
\hline DTP3 & Third dose of the combined Diphtheria, Tetanus, and Pertussis Vaccine \\
\hline EM-DAT & Emergency Events Database \\
\hline GVAP & Global Vaccine Action Plan \\
\hline HPV & Human Papillomavirus \\
\hline JRF & Joint Reporting Form \\
\hline MNT & Maternal and Neonatal Tetanus \\
\hline NIPS & National Immunisation Programmes \\
\hline NITAG & National Immunisation Technical Advisory Group \\
\hline PCV & Pneumococcal Conjugate Vaccine \\
\hline PHE & Public Health Emergency \\
\hline PROMED & Program for Monitoring Emerging Diseases \\
\hline RSPI & Regional Strategic Plan for Immunisation \\
\hline UCDP & Uppsala Conflict Data Program \\
\hline SAGE & Strategic Advisory Groups of Experts in Immunisation \\
\hline UNICEF & United Nations Children's Fund \\
\hline VPDs & Vaccine-Preventable Diseases \\
\hline WHO & World Health Organisation \\
\hline WHO-Afro & World Health Organisation African region \\
\hline
\end{tabular}

\section{Declarations}

\section{Ethics approval}

Ethics waiver to conduct this study was granted by the University of Cape Town, Faculty of Health Sciences, Human Research and Ethics Committee.

\section{Consent for publication}

Not Applicable.

\section{Availability of data and materials}

The datasets used during the current study are available from EM-DAT repository (https://www.emdat.be/), UCDP repository (https://ucdp.uu.se/), PROMEDMail repository (https://wwww.promedmail.org/eafr), WHO Emergency Preparedness and Response database (https://www.who.int/csr/don/archive/year/en/) and the WHO/UNICEF JRF immunisation database (https://www.who.int/immunization/monitoring_surveillance/data/en/)

\section{Competing interests}

The authors have no competing interests to declare.

\section{Funding}

Not Applicable.

\section{Authors Contributions}

BK conceived of the presented idea, provided critical feedback, and helped shape the manuscript. VC extracted and analysed the data and wrote the manuscript. EAD and ECH contributed to the development of the methods and coherence of the manuscript. All authors read, edited, and approved the final 
manuscript.

\section{Acknowledgements}

Not Applicable.

\section{References}

1. The world health report 2007: A safer future: Global public health security in the 21st century. Geneva: World Health Organization. 2007. https://www.who.int/whr/2007/whr07_en.pdf?ua=1. Accessed 4 September 2020.

2. Emergency response framework. Geneva: World Health Organization. 2017. https://apps.who.int/iris/bitstream/handle/10665/258604/9789241512299eng.pdf? sequence=1. Accessed 10 September 2020

3. WHO, Regional Office for Africa. WHO health emergencies programme in the African region: Annual Report 2016. Geneva: World Health Organization. 2017.https://apps.who.int/iris/bitstream/handle/10665/258535/9789290233657-eng.pdf?sequence=2. Accessed 13 September 2020.

4. WHO health emergencies programme. Geneva: World Health Organization 2017. https://www.afro.who.int/fr/node/4258. Accessed 13 September 2020.

5. Inter Agency Standing Committee. Definition of Complex Emergencies.1994.https://interagencystandingcommittee.org/system/files/legacy_files/WG16_4.pdf. Accessed 8 March 2020.

6. COVID-19 public health emergency of international concern (PHEIC). 2020.https://www.who.int/publications/m/item/covid-19-public-health-emergencyof-international-concern-(pheic)-global-research-and-innovation-forum. Accessed 05 October 2020.

7. Grundy J, Biggs BA. The impact of conflict on immunisation coverage in 16 countries. International Journal of Health Policy and Management. 2019;8(4):211.

8. Sphere Association. The Sphere Handbook: Humanitarian Charter and Minimum Standards in Humanitarian Response. 4th ed. Geneva, Switzerland; 2018.

9. Lam E, McCarthy A, Brennan M. Vaccine-preventable diseases in humanitarian emergencies among refugee and internally-displaced populations. Human Vaccines \& Immunotherapeutics. 2015;11(11):2627-36.

10. Phalkey R, Runge-Ranzinger S, Guha-Sapir D, Marx M. Systems impacts of natural disasters- A systematic literature review. Health for Millions. 2010;36:10-25.

11. Guha-Sapir D, van Panhuis WG. Armed conflict and public health: a report on knowledge and knowledge gaps. Brussels: CRED. 2002.

12. Wesseh CS, Najjemba R, Edwards JK, Owiti P, Tweya H, Bhat P. Did the Ebola outbreak disrupt immunisation services? A case study from Liberia. Public Health Action. 2017;7 Supp 1:82-87.

13. Ngo NV, Pemunta NV, Muluh NE, Adedze M, Basil N, Agwale S. Armed conflict, a neglected determinant of childhood vaccination: some children are left behind. Human Vaccines \& Immunotherapeutics. 2020;16(6):1454-63.

14. Guiding principles for immunization activities during the COVID-19 pandemic: WHO. 2020. https://apps.who.int/iris/bitstream/handle/10665/331590/WHO-2019-nCoV-immunization_services-2020.1-eng.pdf?sequence=1\&isAllowed=y Accessed 1 May 2020.

15. Sharif I, Sandra M-J, Amanda G, Prashant Y, Peter B, Kalipso C. Maintaining Essential Services in the Time of COVID-19: Vaccination Delivery in Low- and Middle-Income Countries. Center for Global Development. 2020. https://www.cgdev.org/blog/maintaining-essential-services-time-covid-19-vaccinationdelivery-low-and-middle-income. Accessed 22 November 2020.

16. Katherine EG, Anthony S, Ifedayo A, John O, Shirine V, Kagucia W. Why a campaign to champion all vaccines matters now more than ever: The Conversation. 2020.https://theconversation.com/why-a-campaign-to-champion-all-vaccines-matters-now-more-than-ever-137502. Accessed 22 November 2020.

17. Piot P, Larson HJ, O’Brien KL, N’kengasong J, Ng E, Sow S, Kampmann B. Immunization: vital progress, unfinished agenda. Nature. 2019;575(7781):11929.

18. Moeti M. Measles has now killed more people in DRC than Ebola - and almost all of them are children. United Kingdom: The Telegraph. 2019.https://www.telegraph.co.uk/global-health/science-and-disease/measles-has-now-killed-people-drc-ebola-almost-children/. Accessed 20 February 2020.

19. Vaccination in humanitarian emergencies: Implementation guide. 2017. https://apps.who.int/iris/bitstream/handle/10665/258719/WHO-IVB-17.13eng.pdf? sequence=1. Accessed 5 October 2020.

20. Nnadi C, Etsano A, Uba B, Ohuabunwo C, Melton M, wa Nganda G, Esapa L, Bolu O, Mahoney F, Vertefeuille J, Wiesen E. Approaches to vaccination among populations in areas of conflict. The Journal of Infectious Diseases. 2017;216 Suppl 1:368-372.

21. Gayer M, Legros D, Formenty P, Connolly MA. Conflict and emerging infectious diseases. Emerging Infectious Diseases. 2007;13(11):1625.

22. Connolly MA, Gayer M, Ryan MJ, Salama P, Spiegel P, Heymann DL. Communicable diseases in complex emergencies: Impact and challenges. The Lancet. 2004;364(9449):1974-83

23. WHO/UNICEF. Progress and challenges with achieving universal immunization coverage 2019, WHO/UNICEF estimates of national immunization coverage. 2020.https://www.who.int/immunization/monitoring_surveillance/who-immuniz.pdf. Accessed 20 August 2020. 
24. Strategic Advisory Group of Experts on Immunization. The Global Vaccine Action Plan 2011-2020. Review and lessons learned. Geneva: World Health Organization. 2019. https://apps.who.int/iris/bitstream/handle/10665/329097/WHO-IVB-19.07-eng.pdf?sequence=1\&isAllowed=y. Accessed 20 August 2020.

25. Global Vaccine Action Plan 2011-2020. 2013. https://www.who.int/iris/bitstream/10665/78141/1/9789241504980_eng.pdf?ua=1Accessed 13 March 2020.

26. WHO, Regional Office for Africa. Regional Strategic Plan for Immunization 2014-2020. Brazaville: WHO, Regional Office for Africa. https://www.afro.who.int/sites/default/files/2017-06/oms-ivb-rvap-afro-en-20150408_final_sent140317_0.pdf. Accessed 20 March 2020.

27. Global polio eradication initiative applauds WHO African region for wild polio-free certification. 2020. https://www.who.int/news-room/detail/25-08-2020global-polio-eradication-initiative-applauds-who-african-region-for-wild-polio-free-certification. Accessed 06 October 2020.

28. Global Vaccine Action Plan. Regional vaccine action plans 2016 progress report. Geneva: World Health Organization. 2017. https://www.who.int/immunization/sage/meetings/2016/october/3_Regional_vaccine_action_plans_2016_progress_reports.pdf?ua=1. Accessed 15 September 2020.

29. 2017 Assessment Report of the Global Vaccine Action Plan Strategic Advisory Group of Experts on Immunization. Geneva: World Health Organization. 2017. https://www.who.int/immunization/web_2017_sage_gvap_assessment_report_en.pdf?ua=1. Accessed 2 October 2020.

30. Sato R. Effect of armed conflict on vaccination: evidence from the Boko haram insurgency in northeastern Nigeria. Conflict and Health. 2019;13(1):49.

31. WHO/UNICEF. Immunisation data, statistics and graphics. 2020. https://www.who.int/immunization/monitoring_surveillance/data/en/. Accessed 18 October 2020.

32. WHO, Regional Office for Africa. Progress Report on The African Public Health Emergency Fund. 2017. https://apps.who.int/iris/bitstream/handle/10665/260338/AFR-RC67-INF-DOC-7-eng.pdf?sequence=1\&isAllowed=y. Accessed 4 March 2020.

33. Centre for Research on the Epidemiology of Disasters. The International Disaster Database. 2020. https://www.emdat.be/. Accessed 20 June 2020.

34. Uppsala Conflict Data Program. Uppsala Conflict Data Program-Department of Peace and Conflict Research. 2020. https://ucdp.uu.se/. Accessed 15 June 2020

35. Emergencies preparedness, response. 2020. https://www.who.int/csr/don/archive/year/en/. Accessed 5 July 2020

36. Program for Monitoring Emerging Diseases Mail. PROMED-International Society for Infectious Diseases (PROMED, Anglophone Africa). 2020. https://wwww.promedmail.org/eafr. Accessed 7 July 2020.

37. WHO, Regional Office for Africa. Business case for WHO immunization activities on the African continent 2018-2030. Brazaville: WHO, Regional Office for Africa. 2018.https://apps.who.int/iris/bitstream/handle/10665/272537/9789290234111-eng.pdf?sequence=1\&isAllowed=y. Accessed 20 February 2020.

38. WHO, Regional Office for Africa. Emergency Operations: Annual report. Brazzaville: WHO Regional Office for Africa. 2020. https://reliefweb.int/sites/reliefweb.int/files/resources/WHO-AF-WHE-EMO-01-2020.pdf. Accessed 27 October 2020.

39. WHO, Regional Office for Africa. Emergency Operations: Annual report: saving lives and reducing suffering WHO's work in emergency response operations in the WHO African Region in 2017. Brazzaville: WHO Regional Office for Africa. 2018. https://apps.who.int/iris/handle/10665/275502. Accessed 27 October 2020.

40. Watson JT, Gayer M, Connolly MA. Epidemics after natural disasters. Emerging Infectious Diseases. 2007 Jan;13(1):1.

41. Mugali RR, Mansoor F, Parwiz S, Ahmad F, Safi N, Higgins-Steele A, Varkey S. Improving immunization in Afghanistan: Results from a cross-sectional community-based survey to assess routine immunization coverage. BMC Public Health. 2017;17(1):290.

42. Sambala EZ, Wiyeh AB, Ngcobo N, Machingaidze S, Wiysonge CS. New vaccine introductions in Africa before and during the decade of vaccines-Are we making progress? Vaccine. 2019;37(25):3290-5.

43. Wiyeh AB, Sambala EZ, Ngcobo N, Wiysonge CS. Existence and functionality of national immunisation technical advisory groups in Africa from 2010 to 2016. Human Vaccines \& Immunotherapeutics. 2018;14(10):2447-51.

44. SAGE April 2017 National Immunization Technical Advisory Groups. Background Paper. 2017. https://www.who.int/immunization/sage/meetings/2017/april/1_NITAGs_background_document_SAGE_April_2017.pdf?ua=1. Accessed 3 October 2020.

45. Maternal and Neonatal Tetanus Elimination (MNTE): Progress towards global MNT elimination. 2019. https://www.who.int/immunization/diseases/MNTE_initiative/en/index4.html. Accessed 5 July 2020.

46. Laing SK, Griffiths U, Raza AA, Zulu F, Yakubu A, Bessias S, Ozawa S. An investment case for maternal and neonatal tetanus elimination. Vaccine. 2020;38(9):2241-9.

47. Ridpath AD, Scobie HM, Shibeshi ME, Yakubu A, Zulu F, Raza AA, Masresha B, Tohme R. Progress towards achieving and maintaining maternal and neonatal tetanus elimination in the African region. The Pan African Medical Journal. 2017;27 Suppl 3:24.

48. Njuguna HN, Yusuf N, Raza AA, Ahmed B, Tohme RA. Progress Toward Maternal and Neonatal Tetanus Elimination-Worldwide, 2000-2018. Morbidity and Mortality Weekly Report. 2020;69(17):515.

49. Mihigo R, Okeibunor J, Masresha B, Mkanda P, Poy A, Zawaira F, Cabore J. Immunization and vaccine development: Progress towards high and equitable immunization coverage in the Africa region. Journal of Immunological Sciences. 2018 (1):1.

50. Finkelstein P, Teisch L, Allen CJ, Ruiz G. Tetanus: A potential public health threat in times of disaster. Prehospital and Disaster Medicine. 2017;32(3):339.

51. Raza SA, Avan BI. Eliminating maternal and neonatal tetanus and promoting clean delivery practices through disposable clean birth kits. Frontiers in Public Health. 2019;7:339. 
Table

Due to technical limitations, table 1 is only available as a download in the Supplemental Files section.

\section{Figures}

$\begin{array}{lllll}2010 & & & \end{array}$

\section{Figure 1}

A conceptual framework of initiatives used to inform the choice of the study variables

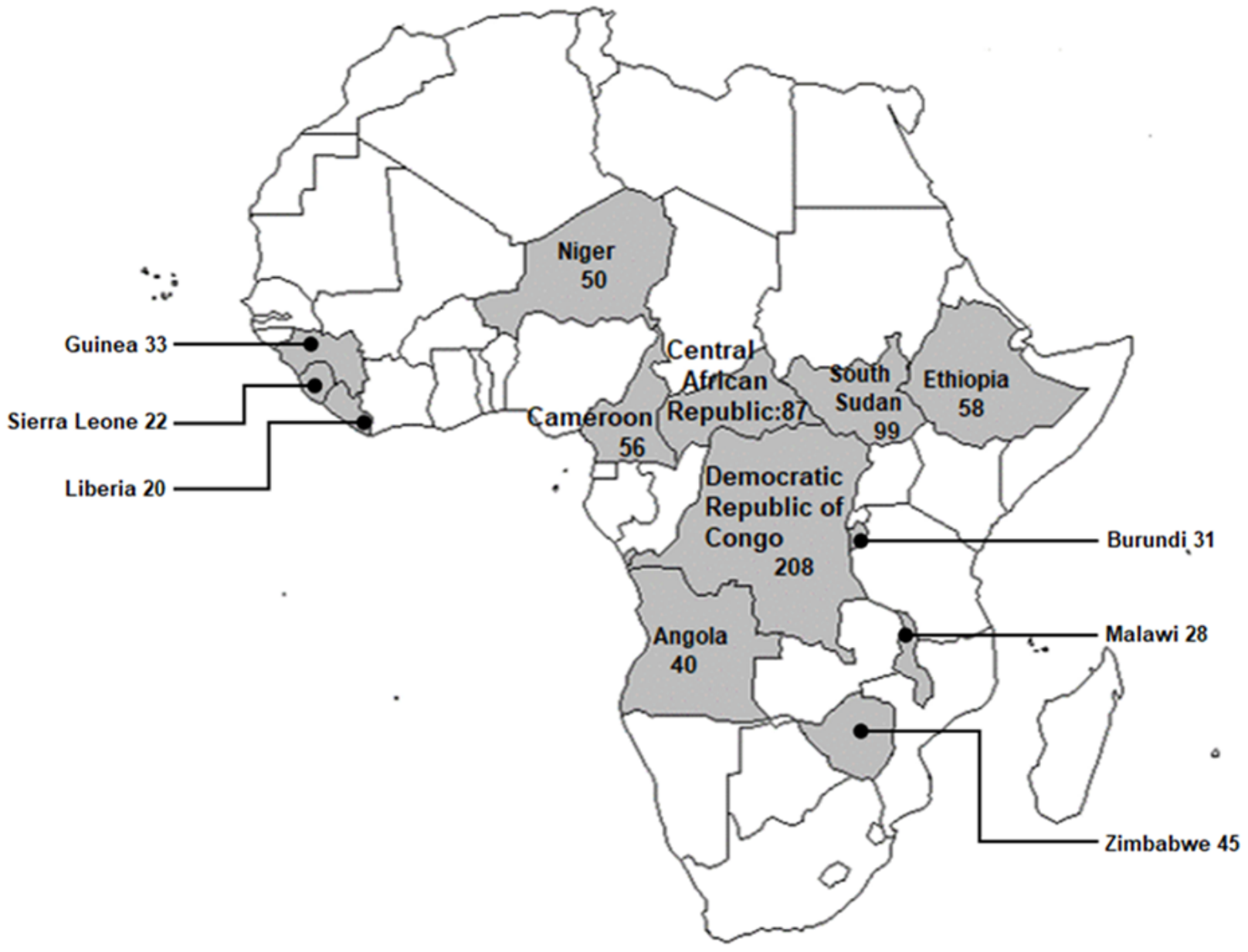

Figure 2 
Distribution of total PHE counts by country from 2010 to 2019 Note: The designations employed and the presentation of the material on this map do not imply the expression of any opinion whatsoever on the part of Research Square concerning the legal status of any country, territory, city or area or of its authorities, or concerning the delimitation of its frontiers or boundaries. This map has been provided by the authors.

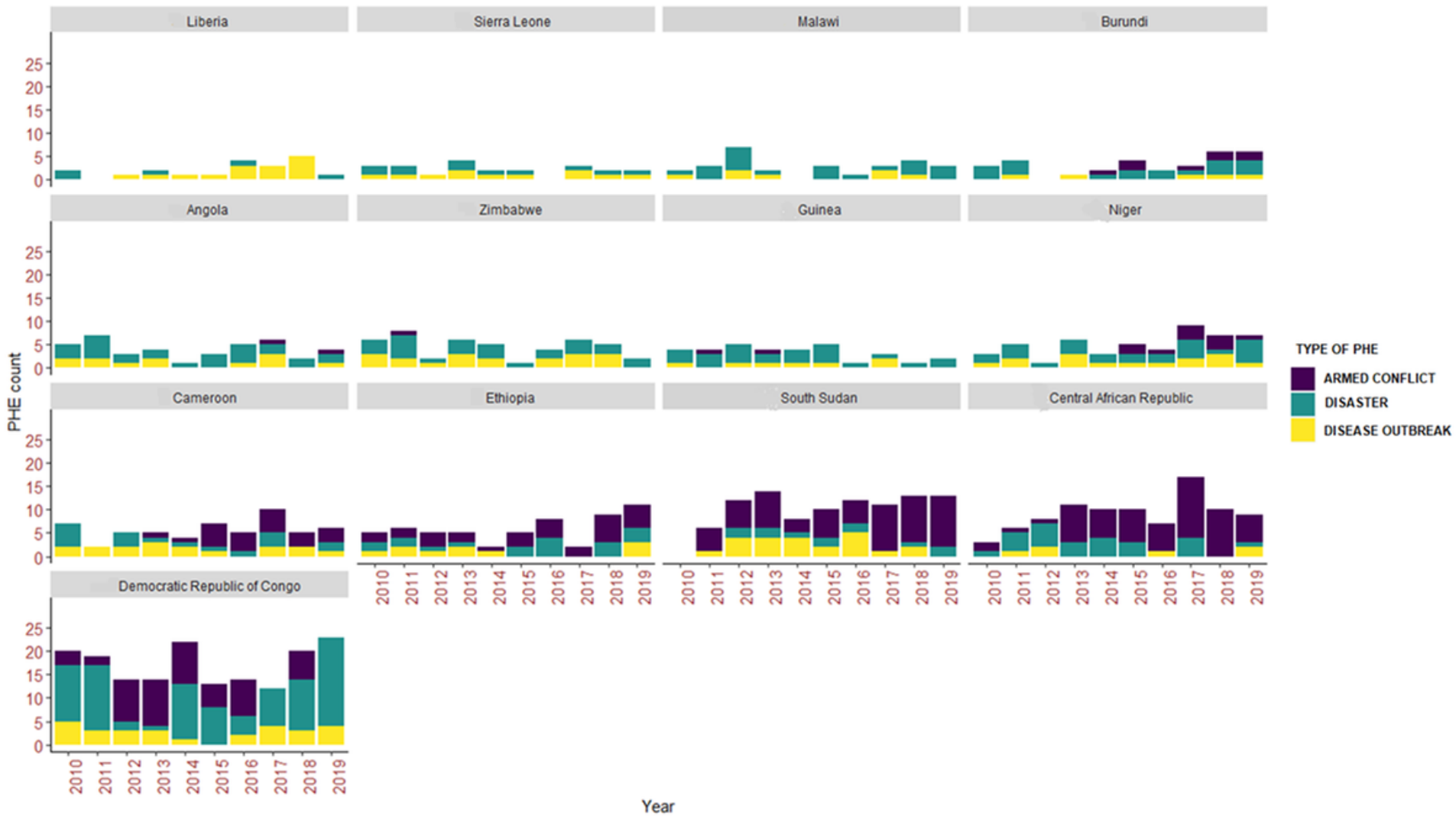

Figure 3

Three types of PHEs recorded in 13 WHO-Afro countries between 2010 and 2019

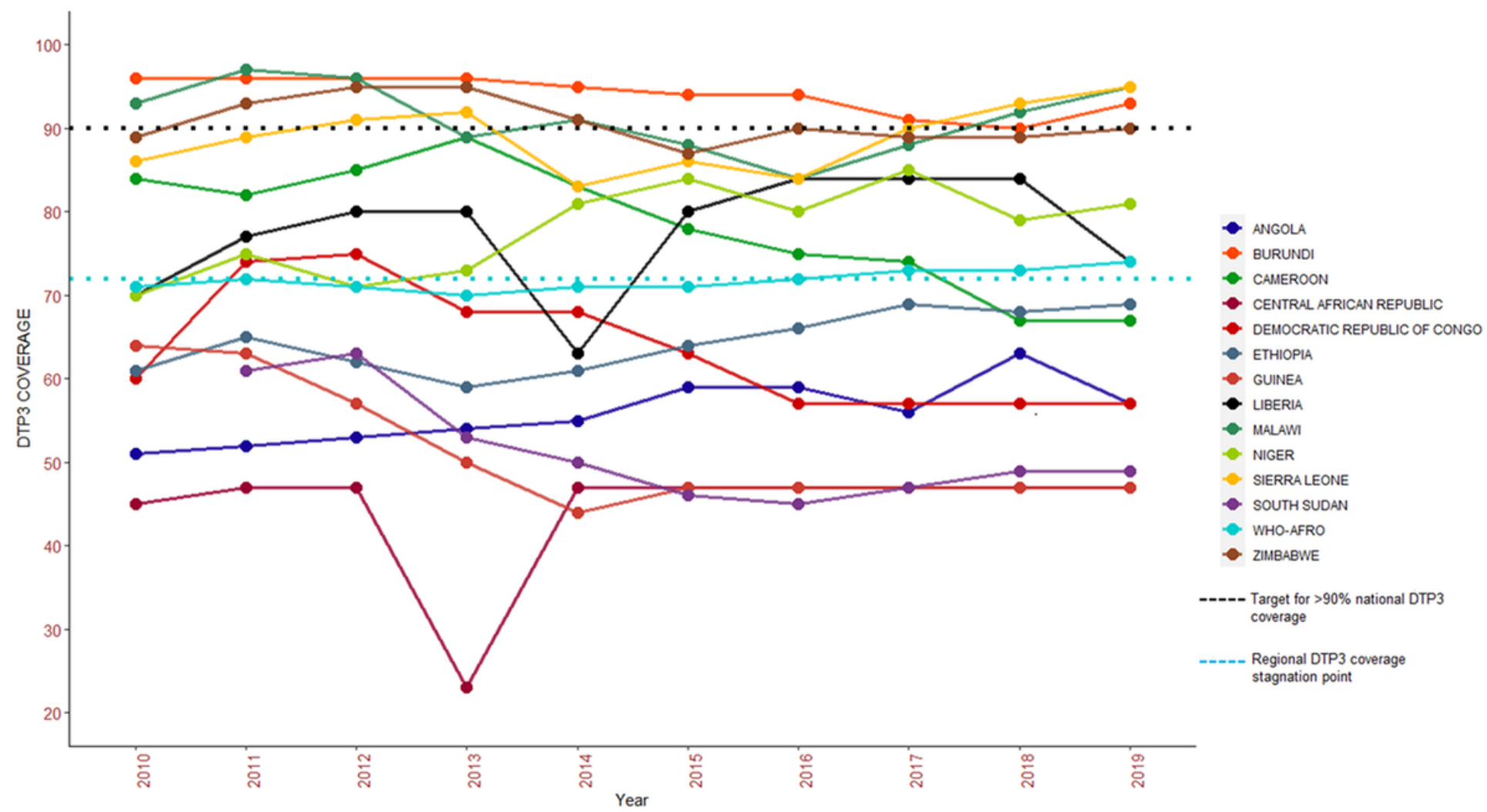

Figure 4 
Annual DTP3 coverage trends between 2010 and 2019 for the 13 countries and the WHO-Afro
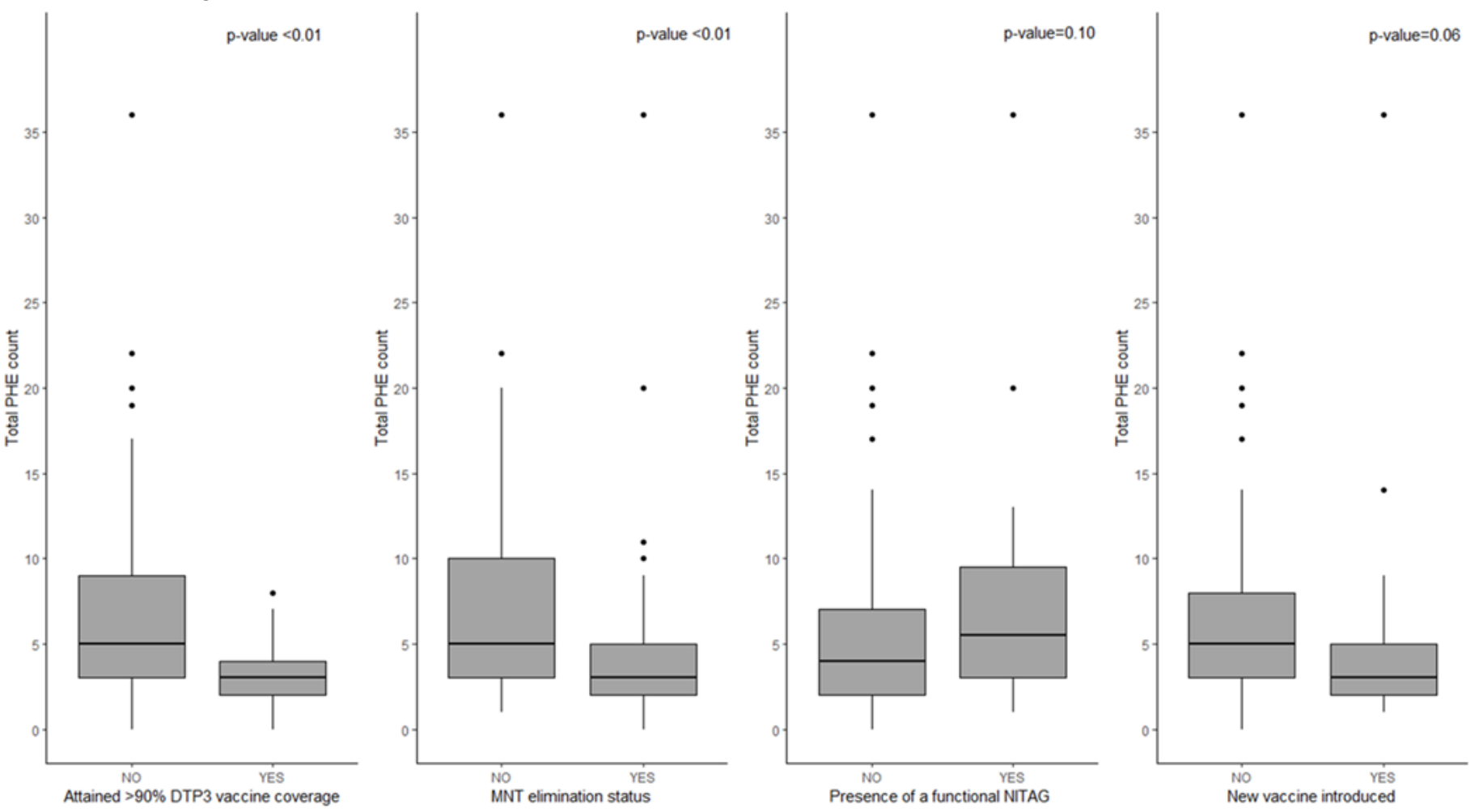

Figure 5

Distribution of immunisation indicators in comparison to total PHE counts in the 13 countries

\section{Supplementary Files}

This is a list of supplementary files associated with this preprint. Click to download.

- Table1.docx 